\title{
Celiac-associated pancreatic disease
}

\author{
Hugh J. Freeman \\ University of British Columbia, Vancouver, BC, Canada
}

Pancreatic disease may be caused by or co-exist with celiac disease. In this setting, endocrine and exocrine changes may occur. As a result, superimposed, severe clinical changes with marked nutritional alteration may result. Importantly, however, in some, endocrine and exocrine pancreatic function may be improved with a gluten-free diet.

Early studies from Europe and the Americas have shown that celiac disease patients have an increased prevalence rate of type 1 diabetes mellitus [1-4]. In part, this relationship was possibly due to sharing of the human leukocyte antigen alleles, DR3, and by linkage disequilibrium, DQ2 [5]. Besides this hypothesized common "immune-mediated" etiopathogenesis, some celiacs with pancreatic disease likely have developed diabetic changes secondarily due to severe exocrine pancreatic failure, in part, related to celiac-induced protein malnutrition.

To further evaluate the prevalence rate of type 1 diabetes in celiac disease, prospective studies using an initial screening IgA tissue transglutaminase antibody assay (tTG) were done at our center in children and adolescents with type 1 diabetes mellitus [6]. A total of 125 male and 108 female patients were evaluated from an established pediatric diabetes clinic. Of these, 15 male and 11 female patients had elevated tTG titers, of whom 19 were also positive for endomysial antibodies. Among these cases, 1 was already known to have celiac disease. Small intestinal biopsies were done in the other 18 children positive for both antibodies. In all, histopathological changes consistent with celiac disease were detected, ranging from increased numbers of intraepithelial lymphocytes to severe crypt hyperplastic villous atrophy (i.e., so-called Marsh 3 lesion). Studies also suggested that serial tTG titers in insulindependent diabetic children might play a useful clinical role in monitoring compliance to a gluten-free diet, possibly of value since close monitoring of compliance of children to a glutenfree diet may be exceedingly difficult. In this study, over $40 \%$ of diabetic children were asymptomatic, and yet, prospective serological screening facilitated selection for small intestinal biopsy evaluation. Overall, $7.7 \%$ of this entire pediatric patient population proved to have typical biopsy features of celiac disease. Remarkably, this rate was confirmed in a more recent

Department of Medicine (Gastroenterology), University of British Columbia, Vancouver, BC, Canada

Conflict of Interest: None

Correspondence to: Dr. Hugh James Freeman, Professor of Medicine (Gastroenterology) UBC Hospital, 2211 Wesbrook Mall, Vancouver, BC, Canada V5Z 1W5, e-mail: hugfree@shaw.ca

Received 27 April 2016; accepted 27 April 2016; Published online 20 May 2016

DOI: http://dx.doi.org/10.20524/aog.2016.0048
European study, published almost a decade later, showing tTG positivity in $8.6 \%$ of diabetic children and adolescents, many again asymptomatic or having non-specific or mild gastrointestinal symptoms [7].

Earlier detection of celiac disease, even in children, with type 1 diabetes is important because of the increased risk for long-term consequences of untreated celiac disease. Most troublesome is the appearance of enteropathy-associated T-cell lymphoma, a disorder that may be reduced in its rate of appearance with a gluten-free diet [8]. Interestingly, 4 cases of lymphoma, celiac disease and type 1 diabetes have been described [9].

Other long-term issues may develop including iron deficiency anemia, osteopenic bone disease, infertility and impaired growth. Poor dietary compliance and delayed diagnosis into later life may be important factors. Improved glucose control with a gluten-free diet has also been noted in type 1 diabetes and concomitant celiac disease [10].

Pancreatic exocrine function may also be significantly changed in celiac disease. Impaired pancreatic function may result in impaired digestion and absorption of critical nutrients along with resultant malnutrition [11]. Logically, in some of these, it is believed that this impairment in nutrition may be made more severe than if only celiac disease alone was present. Some have estimated that up to $20 \%$ or more of celiac patients have defective pancreatic function [12]. In part, this may be due to impaired release of gut-derived peptides crucial to a wellregulated assimilative absorptive process because of mucosal endocrine cell loss. Loss of enteric endocrine cells, including secretin cells [13], have been demonstrated.

Test meal studies in celiac disease have suggested impaired cholecystokinin-pancreozymin secretion leading to a reduction in pancreatic exocrine cell stimulation [14]. Deficiencies of amino acids may result from impaired small intestinal uptake of amino acids (and possibly, small peptides) in some with celiac disease $[12,15]$. Conceivably, this could lead to reduced production of pancreatic enzyme precursors, important for normal pancreatic enzyme hydrolytic activity [15]. Also, altered pancreatic structure may be caused by protein malnutrition including atrophy and fibrosis of the pancreas [11]. Measurements of pancreatic enzyme activities may be reduced with mucosal atrophy and levels were inversely related to the degree of intestinal mucosal damage [16]. In some, severe structural changes of the pancreas have been described, including pancreatic calcification, often associated with chronic or persisting pancreatic inflammation and traditionally associated with excessive use of alcohol. However, protein energy malnutrition appears to be independently associated with kwashiorkor and some patients with celiac disease have shown similar features $[17,18]$. In one celiac with 
pancreatic calcification [18], detailed follow up of intestinal biopsies over several years revealed a prolonged period, albeit, eventual mucosal recovery in spite of a prolonged and strict gluten-free diet alone.

Prior studies have documented increased serum amylase levels in about $25 \%$ of patients raising the possibility of a low-grade pancreatic inflammatory process [19]. Later, in a more recent evaluation [20], exocrine pancreatic function in celiac disease was explored by measuring fecal elastase-1 concentrations along with magnetic resonance imaging (MRI) to evaluate pancreatic structure for morphological changes. Using these methods, 4 of 90 celiacs, or $4.4 \%$, had evidence of pancreatic insufficiency ( 1 mild, 3 severe) while MRI was normal in all 4 of these celiac patients. In a retrospective survey of hospital diagnostic coding from Sweden, a 3-fold increased rate of pancreatitis (from any cause) in celiac disease patients was noted (i.e., 406 of 28908 celiacs) [21]. In contrast, a study from India published in this issue of the Annals of Gastroenterology [22] documents exocrine pancreatic insufficiency in 10 of 36 , or about one-third of young adults (mean age, less than 30 years) based on fecal elastase determinations. Of these, over $80 \%$ showed reversal of elevated fecal elastase values on a gluten-free diet. Most had moderate to severely abnormal small bowel biopsies (i.e., Marsh 2-3C) and only 1 had recurrent bouts of acute pancreatitis. Structural changes based on imaging studies were rarely encountered. Further longer-term studies are now needed to determine if these potentially important observations can be verified by other centers.

\section{References}

1. Saukkonen T, Savilahti E, Reijonen H, Ilonen J, TuomilehtoWolf E, Akerblom HK. Celiac disease: frequent occurrence after clinical onset of insulin-dependent diabetes mellitus. Childhood Diabetes in Finland Study Group. Diabet Med 1996;13:464-470.

2. Maki M, Huupponen T, Holm K, Hallstrom O. Seroconversion of reticulin autoantibodies predicts celiac disease in insulin dependent diabetes. Gut 1995;36:239-242.

3. Fraser-Reynolds KA, Butzner JD, Stephure DK, Trusssell RA, Scott RB. Use of immunoglobulin A-antiendomysial antibody to screen for celiac disease in North American children with type 1 diabetes. Diabetes Care 1998;21:1985-1989.

4. Hill I, Fasano A, Schwartz R, Counts D, Glock M, Horvath K. The prevalence of celiac disease in at-risk groups of children in the United States. J Pediatr 2000;136:86-90.

5. Lie BA, Sollid LM, Ascher H, et al. A gene telomeric of the HLA class I region involved predisposition to both type 1 diabetes and celiac disease. Tissue Antigens 1999;54:162-168.

6. Gillett PM, Gillett HR, Israel DM, et al. High prevalence of celiac disease in patients with type 1 diabetes detected by antibodies to endomysium and tissue transglutaminase. Can J Gastroenterol 2001;15:297-301.

7. Kakleas K, Karayianni C, Critselis E, et al. The prevalence and risk factors of celiac disease among children and adolescents with type 1 diabetes mellitus. Diabetes Res Clin Pract 2010;90:202-208.

8. Holmes GK, Prior P, Lane MR, Pope D, Allan RN. Malignancy in celiac disease-effect of a gluten- free diet. Gut 1989;30:333-338.

9. O'Connor TM, Cronin CC, Loane JF, et al. Type 1 diabetes, celiac disease, and lympohoma: a report of four cases. Diabet Med 1999;16:614-617.

10. Acerini CL, Ahmed ML, Ross KM, Sullivan PB, Bird G, Dunger DB. Celiac disease in children and adolescents with IDDM: clinical characteristics and response to gluten-free diet. Diabet Med 1998;15:38-44.

11. Freeman HJ, Kim YS, Sleisenger MH. Protein digestion and absorption in man. Normal mechanisms and protein-energy malnutrition. Am J Med 1979;67:1030-1036.

12. Corroccio A, Iacono G, Montalto G, et al. Exocrine pancreatic function in children with celiac disease before and after a gluten free diet. Gut 1991;32:796-799.

13. Buchan AM, Grant S, Brown JC, Freeman HJ. A quantitative study of enteric endocrine cells in celiac sprue. J Pediatr Gastroenterol Nutr 1984;3:665-671.

14. Regan PT, DiMagno EP. Exocrine pancreatic insufficiency in celiac sprue: a cause of treatment failure. Gastroenterology 1980;78:484-487.

15. Weinstein LD, Herskovic T. Rectal seepage of oil in a patient with celiac disease and secondary pancreatic insufficiency. Am J Dig Dis 1968;13:762-765.

16. Nousias-Arvanitakis S, Karagiozogluou-Lamboudes T, Aggouridaki C, Malaka-Lambrellis E, Calli-Tsinopoulou A, Xefteri M. Influence of jejunal morphology changes on pancreatic function in celiac disease. J Pediatr Gastroenterol Nutr 1999;29:81-85.

17. Pitchumoni CS, Thomas E, Balthazar E, Sherling B. Chronic calcific pancreatitis in association with celiac disease. Am J Gastroenterol 1977;68:358-361.

18. Freeman HJ, Whittaker JS. Nonalcoholic chronic pancreatitis with pancreatic calcification: presenting manifestation of occult celiac disease. Can J Gastroenterol 1994;8:319-322.

19. Carroccio A, Di Prima L, Scalici C, et al. Unexplained elevated serum pancreatic enzymes: a reason to suspect celiac disease. Clin Gastroenterol Hepatol 2006;4:455-459.

20. Vujasinovic M, Tepes B, Volfand J, Rudolf S. Exocrine pancreatic insufficiency, MRI of the pancreas and serum functional markers in patients with celiac disease. Postgrad Med J 2015;91:497-500.

21. Sadr-Azodi O, Sanders DS, Murray JA, Ludvigsson JF. Patients with celiac disease have an increased risk for pancreatitis. Clin Gastroenterol Hepatol 2012;10:1136-1142.

22. Rana SS, Dambalker A, Chhabra P, et al. Pancreatic exocrine insufficiency in celiac disease: is it due to structural alterations in pancreatic parenchyma? Ann Gastroenterol 2016; (in press). 